\title{
Cost-effective medium-power charging station for public transport vehicles
}

\author{
Martin Jara, Vojtech Blahnik \\ Regional Innovation Centre for Electrical Engineering \\ University of West Bohemia \\ Pilsen, Czech Republic \\ jara@rice.zcu.cz, lucke@rice.zcu.cz
}

\begin{abstract}
Charging stations are becoming an important part of the modern urban infrastructure. This paper describes a concept of a standalone cost-effective medium power charging station dedicated for electric bus charging. It is based on a voltage-source active rectifier operating in both current and voltage mode supplied by low voltage power grid. Appropriate model and simulation of the station at the power level of $300 \mathrm{~kW}$ are provided.
\end{abstract}

Keywords-charging stations; electric bus; Electric vehicle

\section{INTRODUCTION (HEADING 1)}

Electric Vehicles (EV) are expected to be a significant contribution to the air pollution reduction in the urban area in the following years. Their successful deployment in the public transportation systems requires building the efficient charging stations networks. Their basic structure design involves the effects of an actual landscape, population density, available power sources and a number of other factors [1][2].

While in the area of personal electric vehicles the charging stations are more or less standardized depending on delivered power level according to SAE or IEC agencies in case of electric busses such standards don't exist or are under development [3].

The charging station power level in case of public transport system depends on chosen strategy of charging points along the traffic line. The station can be placed at the line end stop or throughout the line. It affects the charging time and the power level as well. Usually the charging interval in minutes is acceptable at the end stations while the interval of several tens of seconds is a top for the in between stop. One of the he categorization of the charging station is related to those charging times. Fast charging and ultra-fast charging station are terms often used in the literature their differentiation depends on the source. According to [4] an ultra-fast charging station is able to charge a vehicle under one minute. Power level could be over 240W (which is a maximum of level 3 charger in [1]) up to $700 \mathrm{~kW}$. A DC charging is usually supposed for the busses as that minimizes the on-board electrical equipment.
Another division of the charging stations is between the standalone ones and the stations for multiple vehicles charging (Figure 1. The latter ones are often proposed as a part of a larger complex with medium voltage infrastructure or intermediate DC bus supplied by the power grid and various other sources like wind generators and solar plants [5] [6][7] .

Standalone charging stations are supplied by a local power grid of either medium or low voltage. Especially in the second case energy storages are often used to cover the peak power during the charging.

This paper focuses on the proposal of a power converter topology, which would serve as an interface between the three-phase low-voltage AC power grid $\left(400 \mathrm{~V}_{\mathrm{AC}}\right)$ and the Electric Vehicle $(\mathrm{EV})$ battery stack. a)

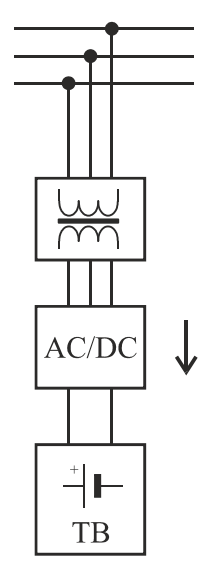

b)

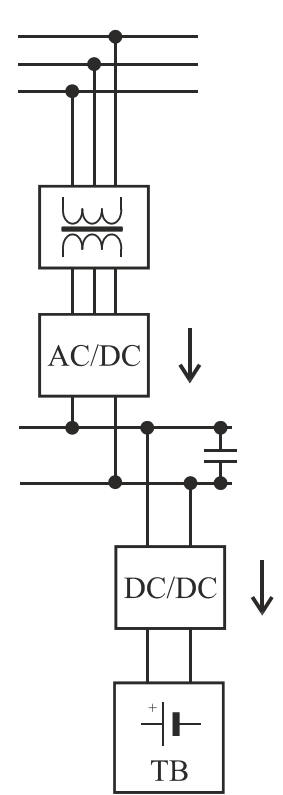

Figure 1. Basic topology of the charging station: a) standalone charging station, b) distributed charging

\section{TOPOLOGY SELECTION}

Since the cost of the charging station converter is often a major concern. The simplest topology should be taken into account. Figure 2. show selection of the basic topologies suitable for battery charging. First one is a current-source thyristor rectifier. Second topology 
consists of a diode rectifier and a post-regulator. Major disadvantages of these topologies lie in their negative influence on the power grid, especially the phase shift and high content of the harmonics. The third one is based on the voltage-source active rectifier with current output. Despite the highest count of the active components this topology was selected as it almost eliminates the effect mentioned above. a)

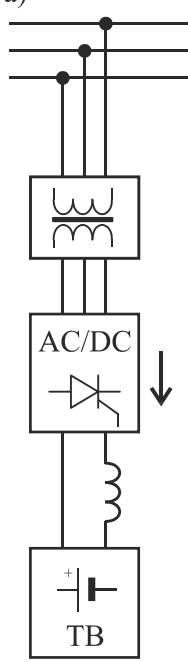

b)

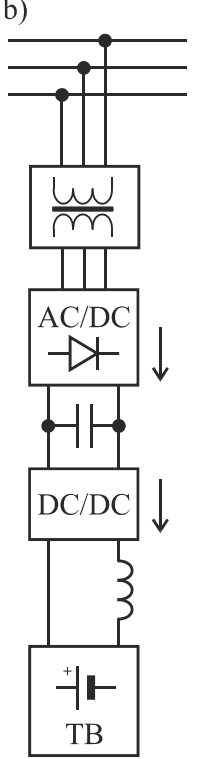

c)

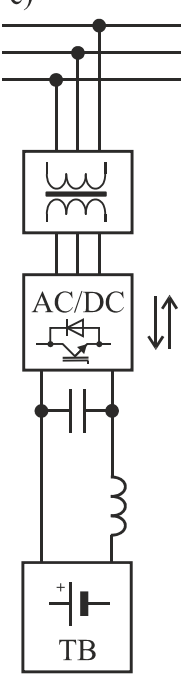

Figure 2. Basic topology of the cost-effective charging station: a) based on thyristor converter, b) with diode rectifier, c) based on active rectifier

\section{SIMULATION OF CHARCHING STATION}

As hinted this paper introduces cost-effective solution of a charging station based on the three-phase voltage-source active rectifier topology (Figure 2. c). The converter construction using this topology is almost a routine task as it is based on fully standardized low - cost power components. On the other hand the control algorithm in this case has to provide functional battery charging management.

This topology is usually employed as an active rectifier with the voltage type output featuring sinusoidal input current and thus power factor closing to 1 . With the proper modification of the control algorithms and an additional inductive filter the properties similar to current output type are feasible as well.

The behavior of the charging station based on the described topology was modeled and simulated using the Matlab/Simulink/Plecs environment. The simulation model is shown in Figure 3. It consists of the input filter, three-phase voltage-source active rectifier including capacitor, output filter and a simplified battery model. The simulation parameters are listed in TABLE I.

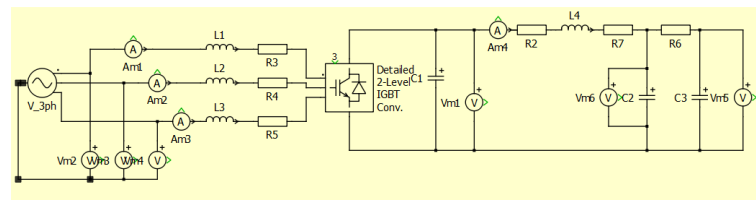

Figure 3. Simulation model of charging station based on active rectifier

TABLE I. PARAMETERS OF THE CHARGING STATION SIMULATION MODEL

\begin{tabular}{|l|l|l|}
\hline \multicolumn{1}{|c|}{ Description } & \multicolumn{1}{|c|}{ Label } & \multicolumn{1}{c|}{ Value } \\
\hline Grid voltage & $\mathrm{U}_{\text {grid }}$ & $230 \mathrm{~V}_{\mathrm{RMS}} / 50 \mathrm{~Hz}$ \\
\hline Induction of input filter & $\mathrm{L}_{\text {input }}$ & $0.2 \mathrm{mH}$ \\
\hline $\begin{array}{l}\text { Parasitic resistance of input } \\
\text { filter }\end{array}$ & $\mathrm{R}_{\text {input }}$ & $50 \mathrm{~m} \Omega$ \\
\hline $\begin{array}{l}\text { Switching frequency of active } \\
\text { rectifier }\end{array}$ & $\mathrm{f}_{\text {switch }}$ & $8 \mathrm{kHz}$ \\
\hline $\begin{array}{l}\text { Dead time duration of active } \\
\text { rectifier }\end{array}$ & $\mathrm{t}_{\mathrm{dt}}$ & $3 \mu \mathrm{s}$ \\
\hline $\begin{array}{l}\text { Capacity of DC-link capacitor } \\
\text { Induction of output filter }\end{array}$ & $\mathrm{C}_{\mathrm{DC}}$ & $10 \mathrm{~m} \mathrm{~F}$ \\
\hline $\begin{array}{l}\text { Parasitic resistance of output } \\
\text { filter }\end{array}$ & $\mathrm{R}_{\text {output }}$ & $1 \mathrm{mH}$ \\
\hline $\begin{array}{l}\text { Serial resistance of batery } \\
\text { model }\end{array}$ & $\mathrm{R}_{\text {sbat }}$ & $10 \mathrm{~m} \Omega$ \\
\hline $\begin{array}{l}\text { Primary capacity of batery } \\
\text { model }\end{array}$ & $\mathrm{C}_{\text {bat1 }}$ & $350 \mathrm{~F}$ \\
\hline $\begin{array}{l}\text { Overflow resistance of batery } \\
\text { model }\end{array}$ & $\mathrm{R}_{\text {inbat }}$ & $0.1 \Omega$ \\
\hline $\begin{array}{l}\text { Secondary capacity of batery } \\
\text { model }\end{array}$ & $\mathrm{C}_{\text {bat2 }}$ & $350 \mathrm{~F}$ \\
\hline
\end{tabular}

The proposed control of the active rectifier employs feed-forward compensation generally used for acceleration. The power grid currents are controlled by the voltage inner control loop driven by current controller which is commanded by a master battery management as shown on Figure 4. The rectifier current control loop use D-Q current control algorithm which is based on vector control in "virtual" revolving reference frame linked to a space vector of the grid voltage. The voltage controller is realized as a conventional PI controller and commands the magnitude of required active component of the input current. The reactive current component is controlled to zero value. The detail description of this vector control including the necessary mathematical theory is possible to find in [8] - [10]. The master current control loop commands voltage value of $\mathrm{C}_{\mathrm{DC}}$ to ensure constant charging current. 


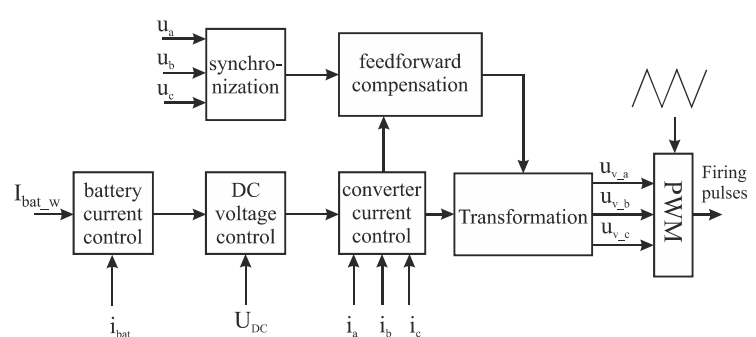

Figure 4. Block diagram of designed control algorithm for battery charger

The resulting grid currents are in phase with the grid voltage and the described control provides highly sinusoidal waveforms of the currents as depicted in Figure 5. and in detail in Figure 6. The harmonic analysis of the grid currents and resulting THD are shown in Figure 7. More comprehensive theory of the voltage-source active rectifiers and their effects on the power grid can be found in [11]. This simulation model involves the influence of the converter deadtimes and their impact on harmonic content [12]. The resulting current THD reaches just $0.42 \%$. This THD was calculated up to the $50^{\text {th }}$ harmonics $(2500 \mathrm{~Hz})$ according to (1) in accordance to the EU standards [13].

$T H D=\sqrt{\sum_{h=2}^{H}\left(\frac{I_{h}}{I_{1}}\right)}$

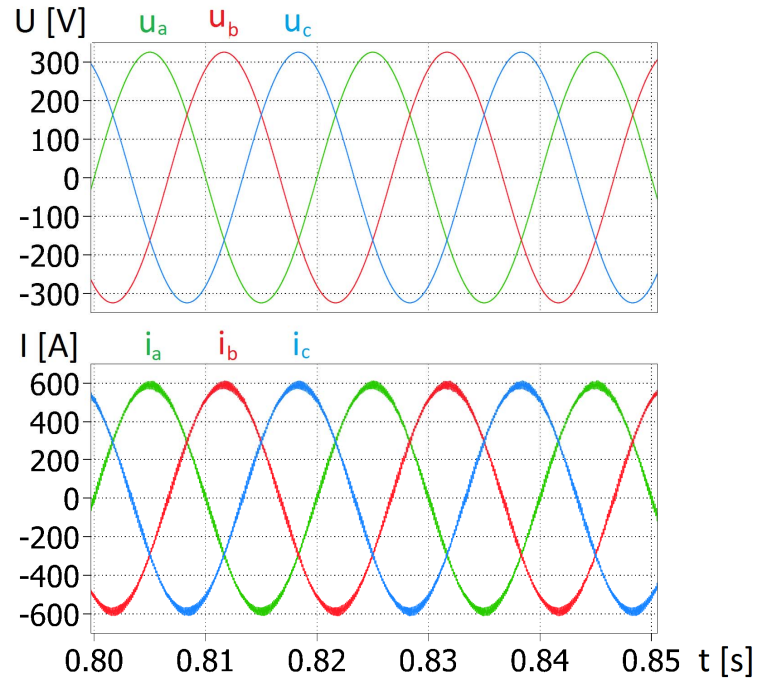

Figure 5. Grid voltages and currents (load power $300 \mathrm{~kW}$ )

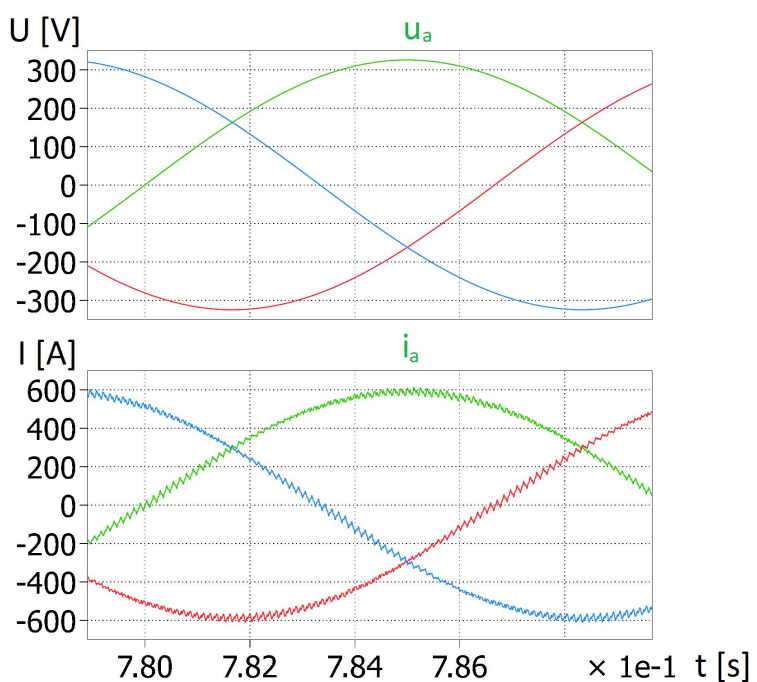

Figure 6. Grid voltage and current in detail

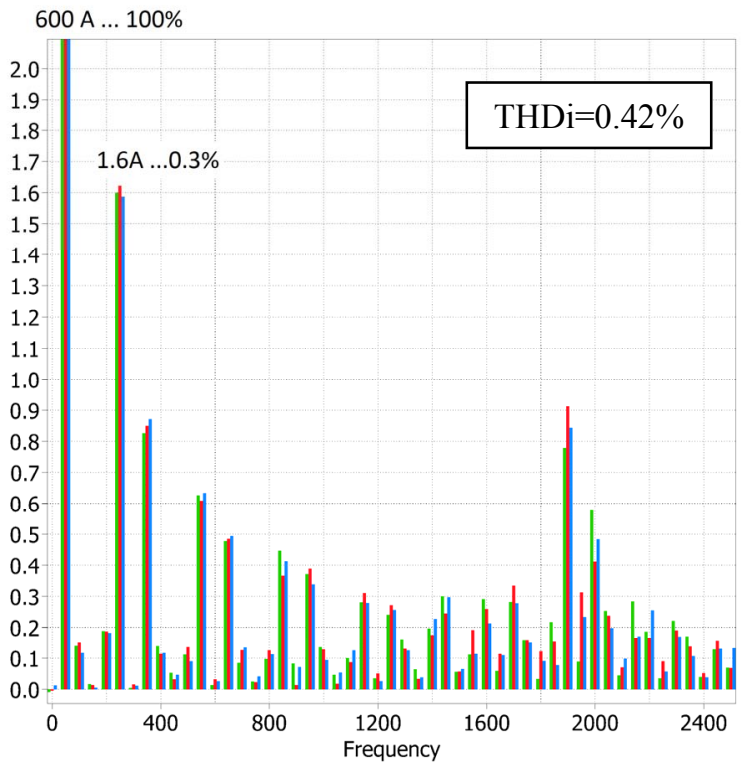

Figure 7. Harmonic analysis of the phase currents under steady-state condition (load power $\mathrm{P}=300 \mathrm{~kW}$ )

As already mentioned the master battery management controls the current control loop and thus provide the charging functionality. At the beginning of the charging cycle in the current mode the current $\mathrm{I}_{\mathrm{bat}}$ is controlled to the required values. Consequently, the battery charger enters constant voltage mode and the current $\mathrm{I}_{\mathrm{bat}}$ is just monitored. The values of the current $\mathrm{I}_{\text {bat }}$ are controlled by a PI controller whose output value represents the required voltage $U_{\mathrm{dcw}}$ for the subsequent voltage controller which is built on conventional control algorithm [8] - [10]. Figure 8. illustrates the situation when the voltage $U_{d c}$ is controlled in order to keep the battery current $\mathrm{I}_{\mathrm{bat}}$ at the constant level. The current mode profile depends on the properties of the concrete battery stack. 


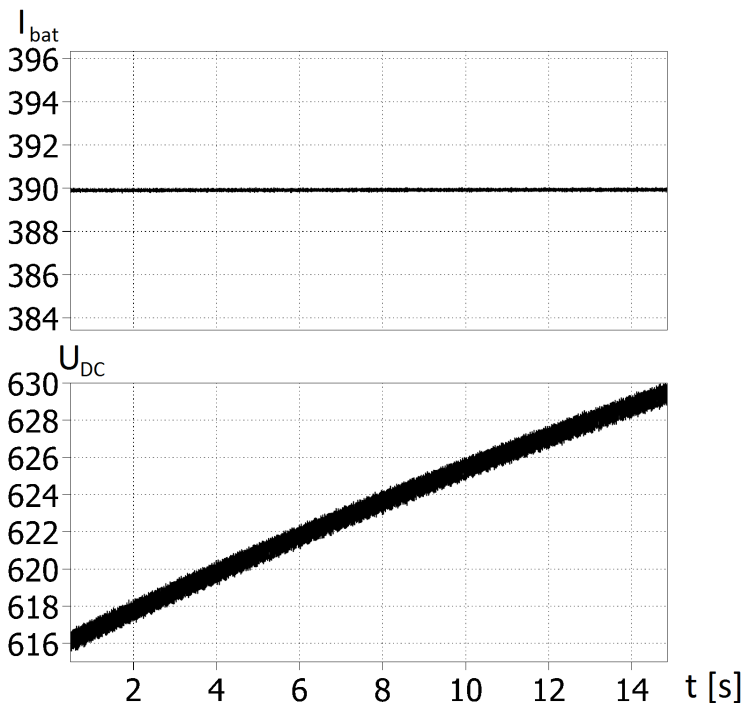

Figure 8. Batery charging current $\mathrm{I}_{\mathrm{bat}}$ and the active rectifier output voltage $\mathrm{U}_{\mathrm{DC}}$

\section{CONCLUSION}

A cost-effective concept of a charging station for electric busses was presented. Low count of the active components in the converter contributes to the system reliability and overall cost. Simulation results together with the proposed control algorithm suggest good regulation properties complying with the battery management requirements.

Future works should be aimed on the issues of the proper connecting to the vehicles' battery stack and the effects of power grid disturbances.

\section{ACKNOWLEDGMENT}

This research has been supported by the Ministry of Education, Youth and Sports of the Czech Republic under the RICE - New Technologies and Concepts for Smart Industrial Systems, project No. LO1607. and project No. SGS-2015-038.

\section{REFERENCES}

[1] M. A. Ríos, L. E. Muñoz, S. Zambrano and A. Albarracín, "Load profile for a bus rapid transit flash station of full- electric buses," Innovative Smart Grid Technologies Conference Europe (ISGT-Europe), 2014 IEEE PES, Istanbul, 2014, pp. 1-6.

[2] Ning Wang, Yun Li and Yafei Liu, "Economic evaluation of electric bus charging infrastructure," Intelligent Transportation Systems (ITSC), 2014 IEEE 17th International Conference on, Qingdao, 2014, pp. 2799-2804.

[3] V. Schwarzer and R. Ghorbani, "Current State-of-the-Art of EV Chargers," EVTC Electric vehicle transportation centre, February 2015.

[4] J. C. G. Justino, T. M. Parreiras and B. J .C. Filho, "Hundreds kW Charging Stations for e-Buses Operating Under Regular Ultra-Fast Charging," Industry Applications, IEEE Transactions on , vol.PP, no.99, pp.1-1.

[5] R. Crosier, Shuo Wan and M. Jamshidi, "A 4800-V gridconnected electric vehicle charging station that provides STACOM-APF functions with a bi-directional multi-level cascaded converter," Applied Power Electronics Conference and Exposition (APEC), 2012 Twenty-Seventh Annual IEEE, vol., no., pp.1508-1515, 5-9 Feb. 2012.

[6] A. R. Sparacino, B. M. Grainger, R. J. Kerestes and G. F. Reed, "Design and simulation of a DC electric vehicle charging station connected to a MVDC infrastructure," Energy Conversion Congress and Exposition (ECCE), 2012 IEEE, vol., no., pp.1168-1175, 15-20 Sept. 2012

[7] G. F. Reed, B. M. Grainger, A. R. Sparacino, R. J. Kerestes and M. J. Korytowski, "Advancements in medium voltage DC architecture development with applications for powering electric vehicle charging stations," Energytech, 2012 IEEE , vol., no., pp.1-8, 29-31 May 2012.

[8] N. A. Losic, L. Cheng and V. Khatri, "Modeling and design of a vector-controlled PWM active rectifier," Industrial Electronics Society, 2001. IECON '01. The 27th Annual Conference of the IEEE, Denver, CO, 2001, pp. 1096-1101 vol.2.

[9] H. Zhang and Y. Zhao, "Vector Decoupling Controlled PWM Rcetifier for Wind Power Grid-Connected Inverter," Energy and Environment Technology, 2009. ICEET '09. International Conference on, Guilin, Guangxi, 2009, pp. 373-376.

[10] M. Taha, "Active Rectifier Using DQ Vector Control for Aircraft Power System," 2007 IEEE International Electric Machines \& Drives Conference, Antalya, 2007, pp. 13061310.

[11] V. Kus and T. Josefova, "Current harmonics of voltagesource active rectifier with random switching frequency," Electric Power Engineering (EPE), Proccedings of the 2014 15th International Scientific Conference on, Brno, 2014, pp. 193-196.

[12] V. Kus and T. Josefova, "The influence of the dead time duration and switching frequency on the input current distortion of voltage-source active rectifiers," Applied Electronics (AE), 2015 International Conference on, Pilsen, 2015, pp. 131-134.

[13] IEC 60050-551-20, "International Electrotechnical Vocabulary, Power Electronics - Harmonic Analysis", 2003. 